\title{
Transzygomatic anterior infratemporal fossa approach and high cervical approach for resection of infra temporal fossa and parapharyngeal space solitary fibrous tumours. Report of 2 cases and review of literature
}

\author{
Kazumi Ohmori ${ }^{1}$, Shiduka Kamiyoshi ${ }^{1}$, \\ Taku Takeuchi ${ }^{1}$, Takanori Fukushima ${ }^{2}$, \\ Takashi Tsuduki $^{3}$, Toshika Arita ${ }^{3}$ \\ 1 Nishinomiya Watanabe Cardiovascular Center, JAPAN \\ 2 Duke University, USA \\ 3 Yao Municipal Hospital, JAPAN
}

\begin{abstract}
The infratemporal fossa (ITF) is the region under the floor of the middle fossa giving passage to most major cerebral vessels and cranial nerves.(1) It is closely related to important adjacent regions such as the middle fossa, pterygopalatine fossa, orbit, and nasopharynx.(2) Due to the anatomical complexity in the ITF, surgical removal of the lesions in or around it is still challenging.(3) Since the 1960s, many surgeons have reported various surgical approaches. the preauricular transzygomatic approach via a transcranial route was reported to be used for exposure of the antero-superior portion of the ITF $(2,3)$. Solitary fibrous tumours (SFTs) were first described by Klempere and Rabin in 1931 as spindle-cell tumours originating from the pleura.(4) With the exception of myopericytoma, infantile myofibromatosis and HPC-like lesions of the sinonasal tract showing myoid differentiation, all other HPC like lesions are best considered as subtypes of SFT.(5) Only a few cases of SFT have been described in the literature involving the skull base and parapharyngeal space.(6-8) The purpose of this article is to show anatomical dissections involving this surgical approach and to evaluate our surgical experience using it.
\end{abstract}

\section{FIRST CASE}

$45 \mathrm{yr}$ old female presented with swelling over left cheek without any neurological deficit. MRI revealed left middle cranial fossa base lesion extending into infratemporal fossa. Patient underwent surgery by left anterior infratemporal fossa approach and gross total excision of lesion. Postoperatively patient developed left V3 dysesthesia, which improved over a period of one month. Biopsy- solitary fibrous tumor



$\nabla$

Corresponding author: Ahmed Ansari

Nishinomiya Watanabe Cardiovascular Center, Japan

ahmed.ansari2@gmail.com

Copyright and usage. This is an Open Access article, distributed under the terms of the Creative Commons Attribution Non-Commercial No Derivatives License (https://creativecommons org/licenses/by-nc-nd/4.0/) which permits noncommercial re-use, distribution, and reproduction in any medium, provided the original work is unaltered and is properly cited

The written permission of the Romanian Society of Neurosurgery must be obtained for commercial re-use or in order to create a derivative work.

ISSN online 2344-4959 (C) Romanian Society of Neurosurgery

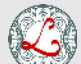

First published December 2019 by London Academic Publishing www.lapub.co.uk 

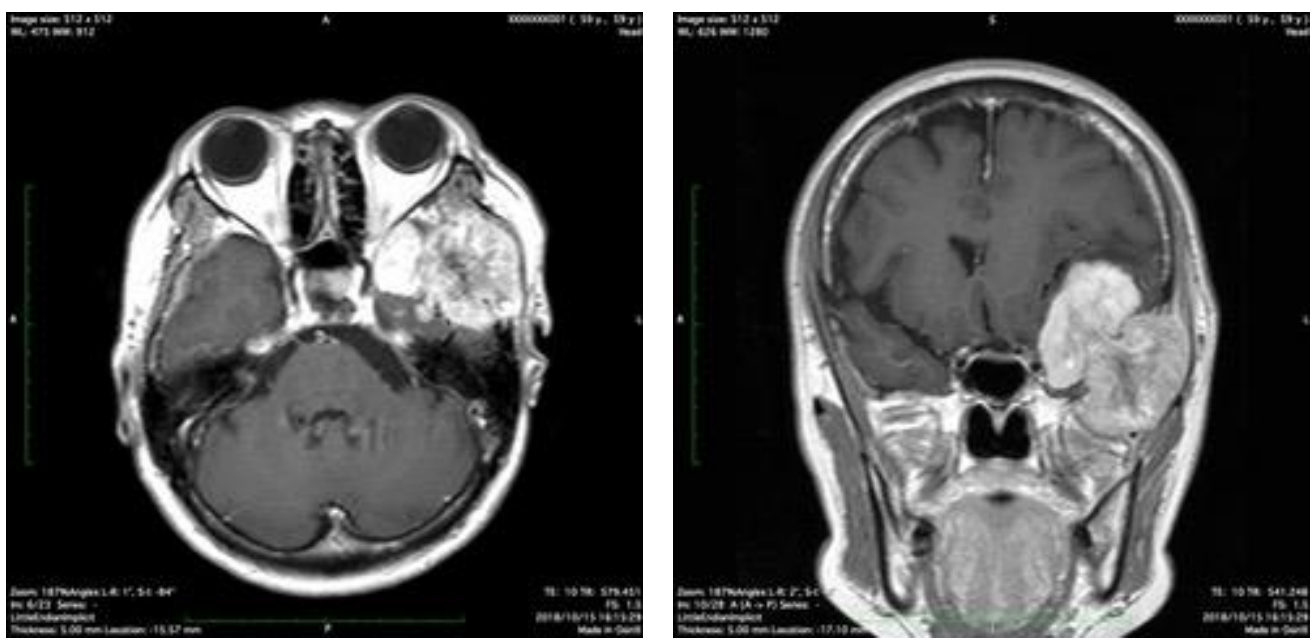

Figure 1: MRI images showing infratemporal fossa tumor with extension into middle cranial fossa.
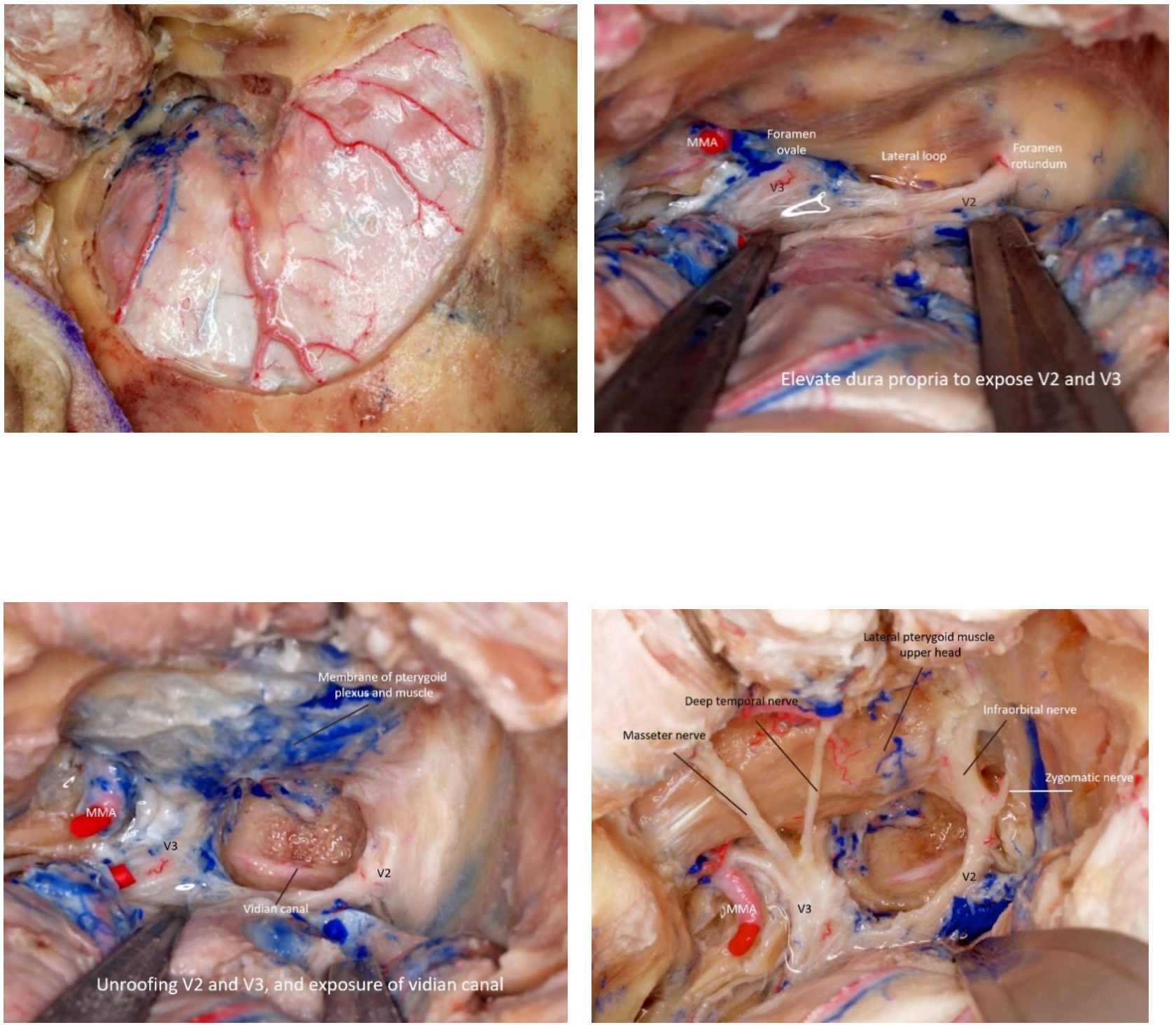

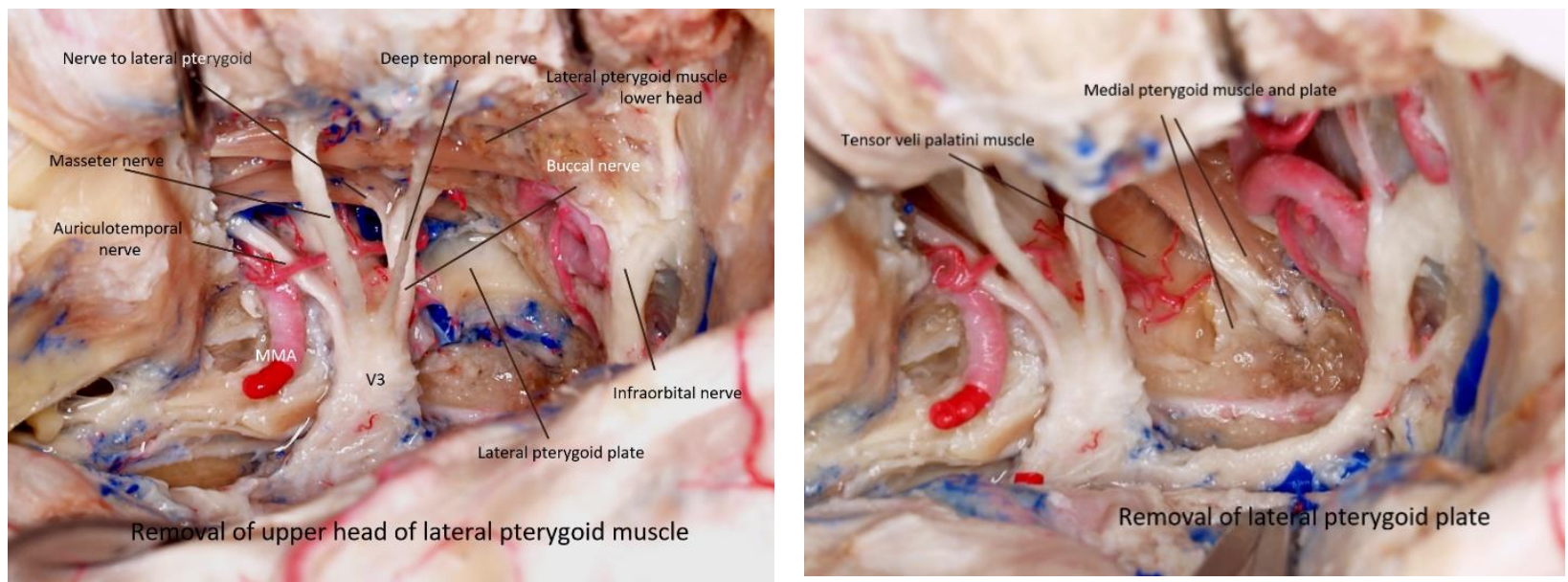

Figure 2: (A-F). A) Frontotemporal craniotomy with elevation of zygomatic arch.
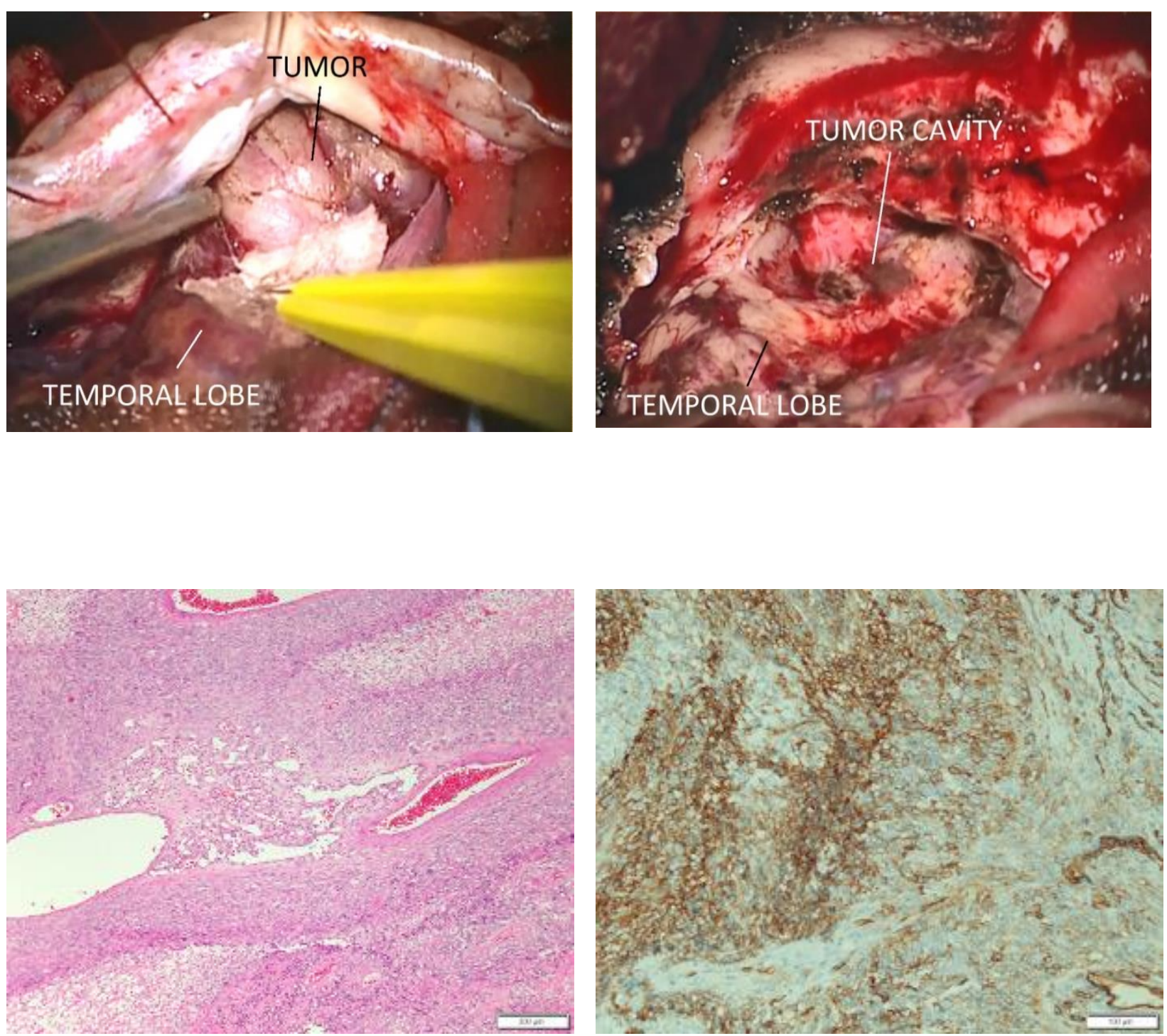


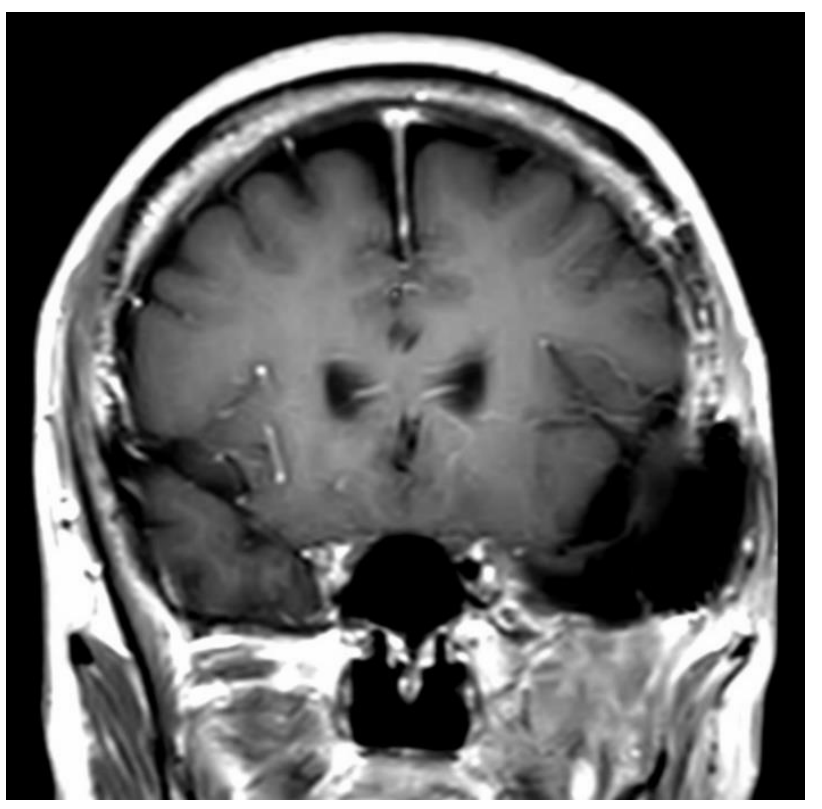

\section{SECOND CASE}

38-year-old male presented with left infra auricular swelling without any neurological deficit. MRI revealed left parapharyngeal space tumor. Patient underwent surgery by high cervical approach and gross total excision of tumor. Biopsy - solitary fibrous tumor.
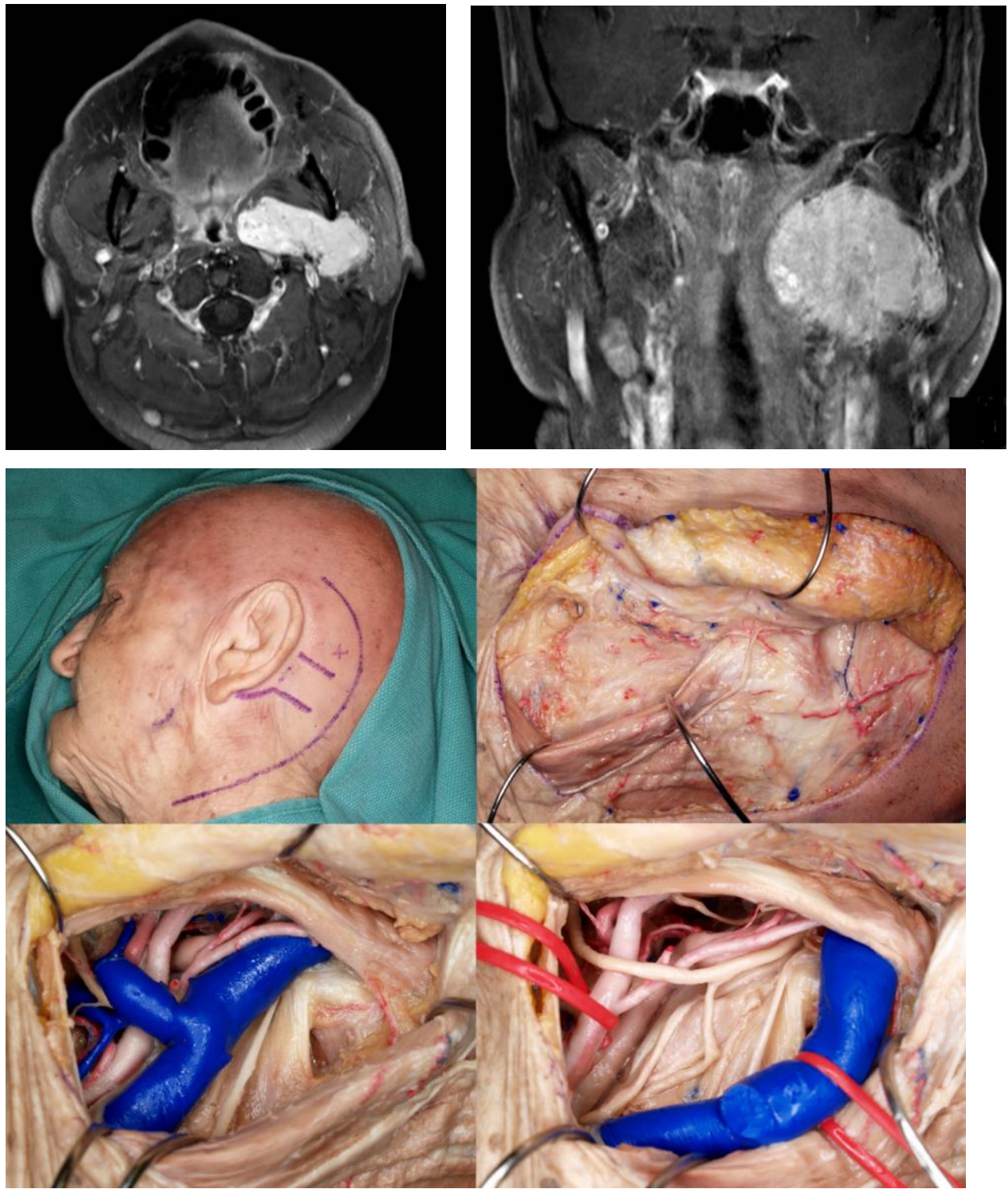

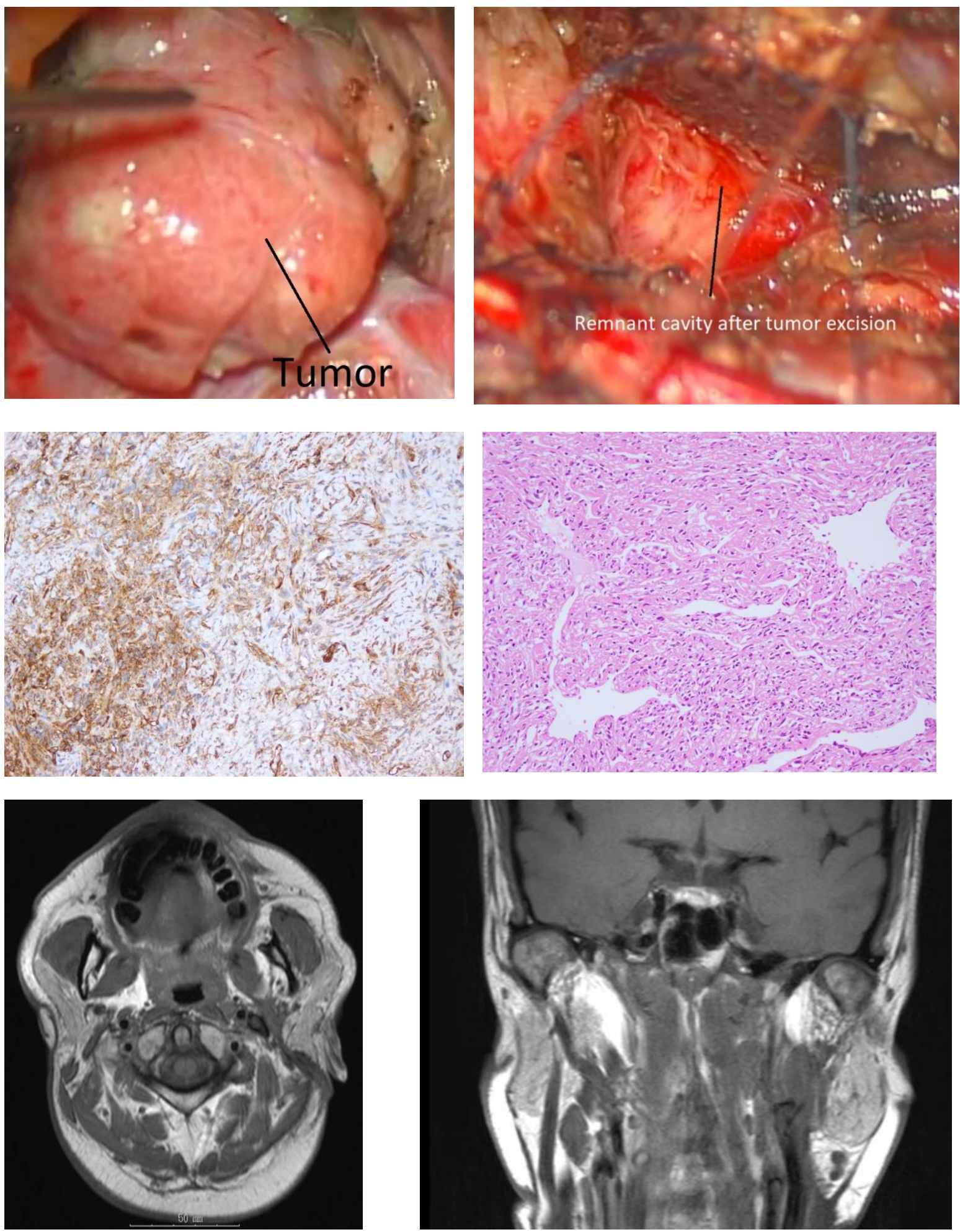

\section{Discussion}

Most cases of soft tissue SFTs occur in the early fifth decade of life.(9). Its occurrence is less than $2 \%$ of all soft tissue tumours.(9)

A study conducted by Demicco et al of 110 cases found about $32 \%$ to be in the abdomen/pelvis, 32\% to be pleural, $16 \%$ in the extremities, $12 \%$ in the trunk, and $12 \%$ in the head and neck.(10)

Skull base SFTs may include a wide variety of symptoms, although they are usually asymptomatic 
on presentation.(11)

The symptoms manifest most frequently as a slowly expanding painless mass. SFTs from any site are usually benign and surgical resection alone is Curative. $(12,13)$

The presence of infiltrative margins with surrounding tissues, high mitotic count $(\geq 4$ mitoses per 10 high-power high fields) of cellular pleomorphism and tumour necrosis also suggests malignancy. $(9,12)$

The main treatment is surgical for benign and malignant SFTs. But when histopathology suggests malignancy or when there are positive surgical resection margins, radiotherapy must be discussed, as for other sarcomas. $(9,14)$

Parapharyngeal space tumours are a rare neoplasm, comprising less than $0.5-1 \%$ of tumours of the head and neck. SFT is very uncommon but should be part of the differential diagnosis in patients with a skull base lesion. Diagnosis is difficult but pathologists should be aware of the classical finding of this disease consisting of spindled cells in a disorganized pattern, with alternating hypocellular and hypercellular areas separated by hyalinized collagen. Immunophenotyping staining positive for the presence of CD34 and Bcl-2 can be useful.

Most important prognostic factor in patients with solitary fibrous tumour is completeness of resection. The pioneers of the ITF were Conley [6] and Barbosa [3].

A variety of surgical approaches to the ITF have been developed. variations include anterior (transfacial, transmaxillary, transoral, and transpalatal), lateral (transzygomatic and lateral infratemporal), or inferior (transmandibular and transcervical) approaches.

Fukushima et al. developed a classification of ITF approaches into three types: anterior, middle, and posterior ITF approaches.

Transcervical approach for parapharyngeal space is the easiest approach for resection of these tumors.(15).

\section{REFERENCES}

1. Bejjani GK, Sullivan B, Salas-Lopez E, Abello J, Wright DC, Jurjus A, et al. Surgical anatomy of the infratemporal fossa: the styloid diaphragm revisited. Neurosurgery. 1998 Oct;43(4):842-52; discussion 852-853.

2. Fukushima T, Nonaka Y. Fukushima manual of skull base dissection. Raleigh, NC: AF-Neuro Video; 2010.

3. Yoshida K, Kawase T, Tomita T, Ogawa K, Kawana H, Yago $\mathrm{K}$, et al. Surgical strategy for tumors located in or extending from the intracranial space to the infratemporal fossaAdvantages of the transcranial approach (zygomatic infratemporal fossa approach) and the indications for a combined transcranial and transcervical approach-. Neurol Med Chir (Tokyo). 2009 Dec;49(12):580-6.

4. Klemperer $P$, Coleman BR. Primary neoplasms of the pleura. A report of five cases. Am J Ind Med. 1992;22(1):131.

5. Gengler C, Guillou L. Solitary fibrous tumour and haemangiopericytoma: evolution of a concept. Histopathology. 2006 Jan;48(1):63-74.

6. Ransom ER, Judy KD, Bigelow DC. Concurrent Cochlear Implantation with Resection of Skull Base Hemangiopericytoma following Sudden Deafness in an Only Hearing Ear. Skull Base Off J North Am Skull Base Soc Al. 2010 Jul;20(4):279-84.

7. Zeitler DM, Kanowitz SJ, Har-El G. Malignant Solitary Fibrous Tumor of the Nasal Cavity. Skull Base. 2007 Jul;17(4):23946.

8. Lee JE, Hong HS, Chang K-H, Kim HK, Park J. Solitary fibrous tumor of the post-styloid parapharyngeal space. Acta Radiol Short Rep [Internet]. 2014 Jul 26 [cited 2019 Aug 18];3(6). Available from: https://www.ncbi.nlm.nih.gov/pmc/articles/PMC4184415/

9. Penel N, Amela EY, Decanter G, Robin Y-M, Marec-Berard P. Solitary fibrous tumors and so-called hemangiopericytoma. Sarcoma. 2012;2012:690251.

10. Demicco EG, Park MS, Araujo DM, Fox PS, Bassett RL, Pollock RE, et al. Solitary fibrous tumor: a clinicopathological study of 110 cases and proposed risk assessment model. Mod Pathol Off J U S Can Acad Pathol Inc. 2012 Sep;25(9):1298-306.

11. Wignall OJ, Moskovic EC, Thway K, Thomas JM. Solitary fibrous tumors of the soft tissues: review of the imaging and clinical features with histopathologic correlation. AJR Am J Roentgenol. 2010 Jul;195(1):W55-62.

12. Gold JS, Antonescu CR, Hajdu C, Ferrone CR, Hussain M, Lewis JJ, et al. Clinicopathologic correlates of solitary fibrous tumors. Cancer. 2002 Feb 15;94(4):1057-68.

13. Suster S, Nascimento AG, Miettinen M, Sickel JZ, Moran CA. Solitary fibrous tumors of soft tissue. A clinicopathologic and immunohistochemical study of 12 cases. Am J Surg Pathol. 1995 Nov;19(11):1257-66.

14. Bowe SN, Wakely PE, Ozer E. Head and neck solitary fibrous tumors: diagnostic and therapeutic challenges. The Laryngoscope. 2012 Aug;122(8):1748-55.

15. KHAFIF V, Segev Y, Kaplan DM, Gil Z, Fliss DM. urgical management of parapharyngeal space tumors: 10-year review. In. 